\section{Work hard, play harder: Veni, vidi, absorpsi}

\author{
Andrew Blood
}

\section{Introduction}

I am writing my own case history as it is time that drug use was viewed in more than a harmful way. I'll first talk about my personal history, albeit in a limited manner because I don't wish to be identified. I'll then talk about my own drug use, concluding with observations about drug use coming from whist is called by some "functional use".

\section{Personal History}

I grew up in your standard Aussie family, dad, mum and three kids. Being the middle boy gave me privileges neither my oldest nor youngest sibling had. I suppose I was lucky to be born in the order I was. Though Christian by family practice, none of us had ever set foot in a church until my sister's wedding.

I suppose we were from the working class, though dad and mum always insisted they did everything for us to get out of that rut, as they saw it. I didn't do all that well in school and played up a fair bit out of boredom until I found something I was interested in: electronics.

I started working as apprentice electrician when I was seventeen. Within six years I had migrated to working in computing - it paid more and wasn't half as sweaty. I did boring background work, fixing other programmer's mistakes, for three years until I found a job that I excelled in and I' $m$ now self-employed.

These days I tend to work on short-term contracts for a couple of months at a time. Sometimes I don't work for three or four months at time. This is as a choice. With my skills and experience I can take the jobs I want knowing that I won't be running out of money any time soon.

I live with my partner and our various pets most of them just visiting while they get their injuries repaired by my slightly mad partner. No kids, just lots of animals underfoot. Fortunately none have bitten my ankles as yet.

\section{Drug Taking History}

I had my first drug when I was fourteen. I did not know it was a drug. It was just a nice looking mushroom that would supposedly make the world prettier. It did. Now that I know it was a drug, I'm glad I didn't know that it was a drug at the time. If I had I wouldn't have tried it and I wouldn't have had one of the most enhancing experiences in my life.

I've dabbled in every drug that I've been able to find. I like many of them (eg. methamphetamines, MDMA, ganja, heroin, kava, LSD). Some I don't like at all and will never have again (eg. morphine, cocaine). There are also drugs I've never tried but am looking to forward to experiencing (eg. Salvia divinorum).

I've had a few bad experiences on drugs. Funny thing about that: it wasn't the drugs that caused the bad experiences. The bad experiences were caused by prohibition.

The first experience, out of only three or four, was: I was sixteen, out with my mates planning our party for after the cricket on Boxing Day. We had a few cones - none of this Victorian tobacco laced crap, this was Queensland. With only a few cones to go, two constables came walking over, took our gear, threw us in the back of the car and take us fifteen clicks out of town to walk back. One of my mates was sick in hospital from dehydration for six days afterwards. I reckon the constables were angry because they only got a few cones.

\footnotetext{
"I came, I saw, I used."
} 
The second experience was: I had a new contract in a city I hadn't been to for three years. I had no way to 'get on' as my only contact had moved up north. So, for the first time, I went to score off the street. Managed to get busted after scoring what looked like some top crystal. I managed to keep my job even though I didn't show up for the first two days of the contract.

I've had many good experiences on drugs. These are the kinds of experiences that never get talked about. So I'm talking about them now.

The first experience, out of many, was: my partner and I hadn't been communicating very well for most of the past two years. With one of us a devoted "techie" and the other a devoted "greenie", sometimes it seemed we had nothing in common. Our life got to the point where we hadn't had sex in six months, catching quick glimpses of one another either getting out of bed or crashing into bed. It was hectic.

We decided to have a week just for us. I scored some tablets (ecstacy), a bit of whiz (amphetamines), heaps of grass and a case of our favourite wines. Our favourite treats from the deli filled the fridge as well as the esky out the back.

We had everything we could possibly need for the next week without leaving our property. We told all of our friends and work mates we were going away for a week. We put the answering machine on and left it on. We settled into our little escape, at home, and began one of the most incredible weeks of our lives.

We had more sex in one week than we'd had in three years. We talked about things that had been building up for years. Best of all, we resolved the issues that were straining us. Seven years on we are still together and still having sex regularly. This experience was enhanced by our choice to use psychostimulants. I dare say we wouldn't have been able to go the places we went without the so-called 'drugs'.

The second experience was: As well as being the work that pays for me to survive, computers are of immense interest to me. I do the paid work because it pays for my little piece of paradise. I do my own computer work because it allows me to make my own little piece of paradise.

At times I've been stuck in my programming. I need a new way of doing what I' $m$ trying to do and nothing that I can think of works. I leave the problem for a while, keeping it in the back of my mind and letting it pop up when it will. Once, whilst tripping with some mates out in the bush I solved a particular problem that had been hounding me for months. I just saw it there, in between the misty connection between the trees and the anthills, floating in that ether-world we are led to believe doesn't exist.

This 'discovery' of mine enabled me to finish my project. I've now applied this little 'discovery' to other aspects of my programming and I' $m$ getting projects finished in half the time.

\section{Conclusion}

It seems ridiculous to me that I've had to hide my identity to protect my life because some of what I have described is currently criminalized by our supposed moral Governments. In my experiences, and there have been many over my more than forty years, the laws relating to drug use have more to blame for the harms that arise from the use drugs. We only ever hear of the bad experiences, of people whose lives are ruined by drugs. It's time for the weight to shift the balance back to equal.

"Drugs are bad", to quote South Park

Not. 